\title{
Clinical profile of patients with acute pancreatitis in a tertiary care centre in Tripura: A retrospective study
}

\author{
Surajit Kumar Das', Saswati Das² \\ ${ }^{1}$ Associate Professor, Department of Surgery, Tripura Medical College \& Dr. BRAM Teaching Hospital, Tripura, \\ ${ }^{2}$ Consultant, Department of Biochemistry, Atal Bihari Vajpayee Institute of Medical Sciences \& Dr. Ram Manohar Lohia \\ Hospital, New Delhi-110001, India
}

Background: Acute Pancreatitis is a common disease with wide clinical variation and its incidence is increasing. Acute pancreatitis is an inflammatory process leading to abdominal pain, progressive destruction of exocrine tissue and in some patients a loss of endocrine tissue as well, with multiple organ failure and high mortality. Severity of acute pancreatitis is linked to the presence of systemic organ dysfunction and/or necrotizing pancreatitis. Aims and Objective: The present study was aimed to study the clinical profile of acute pancreatitis, the etiology and complications of acute pancreatitis received treatment in the Department of Surgery, Tripura Medical College \& Dr. BRAM Teaching Hospital, Agartala, Tripura. Materials and Methods: This was a hospital based retrospective study which was conducted from January 2019 to December 2019. All patients with a diagnosis of acute pancreatitis were included in this study in order to find out the clinical presentations from the available clinical, laboratory and radiological data. Results: Of the 100 patients in this study, 96 were male and 4 were female. Minimum age in our study was 10 years and maximum were 70 years. Maximum numbers of patients were below 45 years of age. Alcohol was identified as the most important etiological factor associated with acute pancreatitis. Among the known etiological factors $90 \%$ of the cases were related to alcoholism and $4 \%$ were due to gall stone disease. Abdominal pain and vomiting were the most common symptoms in our study. Epigastric tenderness was present in $90 \%$ of the cases and guarding/rigidity in $50 \%$ of cases. $14 \%$ patients showed jaundice as a sign of acute pancreatitis. There was no major difference between the CT grading system and clinical grading system. Most of the patients recovered with conservative treatment. Adverse outcome was noted in one patient with acute necrotizing pancreatitis. Conclusion: Acute pancreatitis is one of the leading causes of increase in morbidity and mortality to society. Clinical assessment along with radiological findings correlated well with the morbidity and mortality. Our study identifies alcoholism as one of the most important etiological factors.

Key words: Acute pancreatitis; Etiology; Clinical profile; Outcome

\section{Access this article online}

Website:

http://nepjol.info/index.php/AJMS DOI: 10.3126/ajms.v11i6.29233

E-ISSN: 2091-0576

P-ISSN: 2467-9100

Copyright (c) 2020 Asian Journal of Medical Sciences

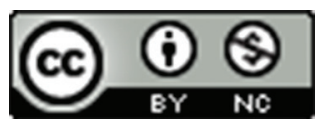

This work is licensed under a Creative Commons Attribution-NonCommercial 4.0 International License.

\section{INTRODUCTION}

The name "pancreas" is derived from Greek word "pan" (all) and "Kreas" (flesh). It was originally thought to act as cushion for stomach. ${ }^{1}$ Acute Pancreatitis is an acute inflammatory process of the pancreas with variable involvement of regional tissues and remote organ system. ${ }^{2}$ The average mortality rate in severe acute pancreatitis approaches $2-10 \%{ }^{3}$ The diagnosis of acute pancreatitis requires two of the following three features: abdominal pain consistent with acute pancreatitis (acute onset of persistent, severe, epigastric pain often radiating to the back), serum lipase activity (or amylase activity) at least three times greater than the upper limit of the normal and characteristic finding of acute pancreatitis on Contrast Enhanced Computed Tomography (CECT) and 
less commonly Magnetic Resonance Imaging (MRI ) or Transabdominal Ultrasonogram. The American College of Gastroenterology (ACG) practice guidelines provide acceptable terminology for the classification of acute pancreatitis and its complications. ${ }^{4}$ Acute pancreatitis is broadly classified (The Atlanta Classification) as mild and severe. The mild acute pancreatitis is often referred to as Interstitial Pancreatitis, based on its radiographic appearance. Severe acute pancreatitis implies presence of organ failure, local complications, or pancreatic necrosis. Interstitial pancreatitis implies preservation of pancreatic blood supply. The attack is mild in almost $80 \%$ of patients who will show marked improvement within 48 hours. In some $20 \%$ of patients however it is severe with high morbidity and mortality. ${ }^{5,6}$ The first twelve hours are extremely important to provide appropriate management which decreases morbidity and mortality. ${ }^{7-9}$

Most cases of acute pancreatitis fall in to the mild category with favorable recovery. However, $15 \%$ to $20 \%$ cases of acute pancreatitis are severe and may result in prolonged hospitalization and local as well systemic complications like Systemic Inflammatory Response Syndrome (SIRS), multi organ system failure and death. ${ }^{10}$ There are many causes of acute pancreatitis but the mechanism by which the condition trigger pancreatic inflammation have not been identified. Nearly $80 \%$ of cases of acute pancreatitis worldwide are caused by gall stone obstruction and alcohol intake. Other causes like hypertriglyceridemia and drugs account for the rest. It is necessary to identify the etiology to institute definitive management and to prevent further attack and to assess the severity for the proper management of patients. According to a retrospective study conducted by Matar ZA in Arab Population $96 \%$ of patients with gall stone were the leading cause. ${ }^{8}$ Early confirmation of etiology by radiological investigation like Endoscopic retrograde cholangiopancreatography (ERCP) and Magnetic resonance cholangiopancreatography (MRCP) within 48 hours and clearance of stone from common bile duct followed by urgent cholecystectomy within 3 to 9 days gave excellent outcome. Early accurate diagnosis of acute pancreatitis is very important for its management. Symptoms of acute pancreatitis vary considerably. For this reason clinician must carefully evaluate information derived from other sources that supplement the history and physical examination including laboratory tests, imaging studies before arriving at a correct diagnosis of acute pancreatitis. If the cause of the attack can be eliminated there will be no further attacks and the pancreas will return to normal in terms of its morphology and function. ${ }^{11}$ In mild attack of pancreatitis, a conservative approach is indicated with intravenous fluid administration and frequent, but non invasive observation. However, if the patient has a severe attack of pancreatitis, then a more aggressive approach is required with the patient being admitted to a high dependency or an intensive care unit where the patient is monitored invasively to ensure haemostatis of cardiovascular, respiratory and renal systems. ${ }^{1}$

Acute pancreatitis is a common disease with wide clinical variation. As there is no detailed study about the clinical profile of acute pancreatitis from the north eastern region of India, this study was conducted to observe the clinical presentations of acute pancreatitis treated in the department of Surgery of Tripura Medical College \& Dr. BRAM Teaching Hospital, Agartala, Tripura, India.

\section{MATERIALS AND METHODS}

This was a hospital record-based study, performed in the Department Of Surgery in Tripura Medical College \& Dr. BRAM Teaching Hospital, Agartala, Tripura, from January 2019 To December 2019 to find out the clinical presentation of acute pancreatitis patients. Institutional Ethics and Research Committee approval was obtained to conduct the study. All age groups and patients of both sexes were included in this study. The diagnosis of acute pancreatitis was based on presence of appropriate clinical evidence associated with an elevation of serum amylase and/or urinary amylase. Patients were classified into mild, moderate, and severe acute pancreatitis based on Ranson's score, Glasgow scoring system..${ }^{14}$ Patients with chronic pancreatitis and malignancy were excluded from the study. On admission detail history were taken. Age, sex, address, symptom and sign were noted carefully. Relevant past history, family history and personal history especially alcohol consumption were recorded. A detailed history was obtained and thorough physical examination was carried out for every subject included in the study, as per the pre-designed proformas. Age, sex, address, symptoms and signs were noted. Relevant past history, family history and personal history, especially history of alcohol consumption were recorded. Associated medical disease, like hypertension, diabetes mellitus, chronic renal failure, bronchial asthma, chronic obstructive pulmonary disease (COPD) and ischemic heart disease were noted. Results of haematological, biochemical and imaging tests were noted. The most likely etiological factor was identified by analyzing history, physical examination and relevant investigations. Investigations like routine blood test, DC, WBC count, blood sugar estimation, routine urine examination were done. Specific investigation like serum lipase estimation was also done. Ultrasonography of whole abdomen and pelvis were done in all patients to evaluate for the presence of gall stones and common 
bile duct pathology. CT scan was done after 72 hours of admission. MRCP was done in selected and confusing cases. All patients were initially subjected to conservative measures.

\section{Inclusion criteria}

- All patients who have been diagnosed to have acute pancreatitis by clinical examination, supported by USG, CT abdomen.

- Patient of all age group and both sexes.

Exclusion criteria

- Cases with incomplete documentation

- Chronic Pancreatitis and pancreatic malignancy

\section{RESULT}

In the present study most of the patients were in the age group of $20-39$ years $(63 \%)$ followed by $40-59$ years $(28 \%), 4 \%$ in less than 20 years and $5 \%$ in the age group of $60-80$ years.(Table 1) Study subjects composed of both males and females. Males contributed $96 \%$ of the patient population and females were $4 \%$ only (Table 1 ). In our study alcohol was identified as the most important etiological factor associated with pancreatitis (Table 2). History of gall stones was found in $4 \%$ of cases and history of infections was also found in $4 \%$ of the cases. Both the features were present in the male patients. Abdominal pain $(100 \%)$ and vomiting $(85 \%)$ were the most consistent symptoms in our study (Table 3).

Among the 100 patients studied 83 had mild pancreatitis, 3 had severe pancreatitis and 14 patients had acute on chronic pancreatitis (Table 4). One patient of acute necrotizing pancreatitis required intensive Care Unit (ICU) admission and developed organ failure indicating adverse outcome (Table 5). As demonstrated in table no 4 and 5 the clinical and CT grading findings corroborate with each other.

\section{Table 1: Age and gender wise distribution of cases}

\begin{tabular}{lcc} 
Age (years) & Male & Female \\
\hline Below 20 & 4 & 0 \\
$20-39$ & 63 & 0 \\
$40-59$ & 24 & 4 \\
$60-80$ & 5 & 0 \\
Total & 96 & 4 \\
\hline
\end{tabular}

Table 2: Patient distribution based on $\mathrm{h} / \mathrm{o}$ alcohol consumption

\begin{tabular}{lcc} 
Alcohol & $\mathbf{N}=$ no. of patients & Percentage (\%) \\
\hline Yes & 90 & 90 \\
No & 10 & 10 \\
Total & 100 & 100 \\
\hline
\end{tabular}

\section{DISCUSSION}

This was a hospital record based retrospective study on one hundred (100) cases of acute pancreatitis. Only those cases who were admitted in Tripura Medical College from January 2019 to December 2019 were subjected to study. Acute pancreatitis is a major surgical challenge to general Surgeons. ${ }^{9,12,13}$ It is a complex condition which varies from mild self-limiting inflammation to rapidly deteriorating condition which poses a serious threat to life. ${ }^{14,15}$ An early and accurate diagnosis of the diseased and rapid institution of therapy might reduce the morbidity and mortality. ${ }^{16}$ If the etiological factor/factors are known and can be eliminated, further attacks can be prevented. Clinical criteria i.e. Ranson's criteria, Glasgow scoring system and radiological scoring system can be used for diagnosis and appropriate management. ${ }^{17}$

In this study the age range of the patient was 10 to 70 years with a peak incidence was in the third and fourth decade (63\%). Besselink MG et al. ${ }^{18}$ found median age of presentation as 53 years. However in our study the median age of presentation was 36.5 years. This can be explained by more alcohol consumption in middle aged males as compared to other age groups. This is comparable to the studies done by Negi et $\mathrm{al}^{19}$ where $47.15 \%$ were in the age group of $41-60$ years and $43.91 \%$ were in the age group 18-40 years. However, the peak incidence at the age of 30 years was reported in a study done by Baig et $\mathrm{al}^{20}$ indicating younger age group being affected. In USA, Western Europe and Asia gall stones are the most common cause of acute pancreatitis and alcohol is the second most common cause. However the variation of etiology of pancreatitis depends on country of origin. In our study most cases $(90 \%)$ were due to consumption of alcohol. In our study $4 \%$ of the patients had documented gall stone induced pancreatitis. Sivsankar A et $\mathrm{al}^{21}$ found alcohol consumption in $45.8 \%$ of cases and biliary microlithiasis in $8.3 \%$ of cases. In a study by Ramu $\mathrm{R}$ et al in Kerala, ${ }^{22}$ alcohol induced pancreatitis was higher (42.431\%) followed by idiopathic pancreatitis $(36.926 \%)$. In another study by Vengadakrishnan et al in Chennai alcohol induced pancreatitis was found to be higher $(51 \%){ }^{23}$

In our study, the most common symptom observed was abdominal pain $(100 \%)$ followed by vomiting $(85 \%)$ and fever (3\%). This correlates with the studies by Negi et al, ${ }^{19}$ where vomiting $42.27 \%$ and fever $22.4 \%$ were seen respectively. In the study done by Ahmed K et al, ${ }^{16}$ the most common symptoms were upper abdominal pain $(96 \%)$, nausea and vomiting (88\%), abdominal distension (40\%) and fever $(12 \%)$ which correlates with our study. Similar findings were observed in the study done by Raghuwanshi S et al., in which the triad of epigastric pain, nausea and vomiting was seen in $75 \%$ patients. ${ }^{24}$ 
Table 3: Patient distribution based on symptoms and signs

\begin{tabular}{|c|c|c|c|c|c|}
\hline Symptom & $\mathrm{N}=$ no. of patients & Percentage (\%) & Signs & Frequency & Percentage (\%) \\
\hline Abdominal pain & 100 & 100 & Epigastric tenderness & 90 & 90 \\
\hline Vomiting & 85 & 85 & Guarding & 50 & 50 \\
\hline Abdominal distention & 12 & 12 & Jaundice & 14 & 14 \\
\hline \multirow[t]{2}{*}{ Fever } & 3 & 3 & Shock & 2 & 2 \\
\hline & & & Paralytic ileus & 3 & 3 \\
\hline
\end{tabular}

\begin{tabular}{|c|c|c|c|c|c|}
\hline Clinical Grade & $\mathrm{N}=$ no of patients & Hospital stay in days (average) & ICU admission & Organ failure & Mortality \\
\hline Acute oedematous(mild) & 83 & $10 \pm 2$ & 0 & 0 & 0 \\
\hline Acute on chronic pancreatitis & 14 & $8 \pm 2$ & 0 & 0 & 0 \\
\hline Total & 100 & & & & \\
\hline
\end{tabular}

\begin{tabular}{|c|c|c|c|c|c|}
\hline CT grade & $\mathrm{N}=$ no of patients & Hospital stay in days (Avg) & ICU admission & Organ failure & Mortality \\
\hline Normal & 10 & 7 & 0 & 0 & 0 \\
\hline Grade 1-2 & 72 & $10 \pm 2$ & 0 & 0 & 0 \\
\hline Grade 3-5 & 18 & $15 \pm 2$ & 1 & 1 & 0 \\
\hline Total & 100 & & & & \\
\hline
\end{tabular}

The clinical presentation varies from case to case, depending on severity of acute pancreatitis and any under lying co-morbidities. Mild acute pancreatitis present with minimal organ dysfunction and uneventful recovery, while severe acute pancreatitis is associated with local and systemic complications and high mortality. In our study 83 patients were diagnosed as mild (acute oedematous pancreatitis) type with less hospital stay than severe (acute necrotizing pancreatitis) type. Only one patient required ICU admission. There was no mortality. Similar results were obtained in a study done by Ramu R et $\mathrm{al}^{22}$ in Kerela where $82.1 \%$ cases were mild and Ahlawat et $\mathrm{al}^{25}$ study in North India where $82 \%$ cases were classified as mild. Early identification of patients who are at high risk of developing complications and repeated clinical evaluation may have significant therapeutic implications. In the patient population studied it is evident that alcoholism is the main etiological factor as compared to history of gall stones and infections.

Our study was conducted in a resource limited setting with no external funding. One of the limitations of our study was a small sample size. A prospective clinical study is required to strengthen the present study findings.

\section{CONCLUSION}

Acute pancreatitis is one of the leading cause of increased morbidity and mortality to society. This is the first known study on the clinical profile of acute pancreatitis in the northeastern region of India. Out of the 100 patients studied, maximum numbers of patients were in the third and fourth decade $(63 \%)$ of life. A higher number of male patients presented with the disease $(96 \%)$ as compared to females (4\%). In our study population pain abdomen, nausea and vomiting were the most common symptoms. Clinical assessment along with laboratory markers correlated well with morbidity and mortality. Patients with necrotizing pancreatitis had adverse outcome. Our study identifies alcoholism as one of the most important etiological factors.

\section{REFERENCES}

1. Williams Norman, S. Bailey \& Love's short practice surgery, $27^{\text {th }}$ ed. 2018; 1212-39.

2. Boon NA, College NR, Walker BR, Hunter AA. Davidson's principles and practice of medicine. London, Churchill Living stone, $20^{\text {th }}$ ed. 2006; 904-9.

3. Singh VK, Bollen TL and Wu Bu. An assessment of the severity of Interstitial pancreatitis. Elm Gastroenterol Hepatol. 2011; 9:1098.

https://doi.org/10.1016/j.cgh.2011.08.026

4. Banks PA. Practice guidelines in acute pancreatitis. Am J Gastroenteology. 1997;92:377-386.

5. Banks $P$ and Free $M$. Practice guidelines in acute pancreatitis. Am J Gastroenterology. 2006; 101(10): 237-400. https://doi.org/10.1111/j.1572-0241.2006.00856.x

6. Bardley El. A clinically based classification system for acute pancreatitis. Arch Surg, 1993; 128(5): 586-589. https://doi.org/10.1001/archsurg.1993.01420170122019

7. Skife $P$ and Kingsworth AN. Acute pancreatitis assessment and manage meut: Post Grad Med J. 1996; 72: 277-283.

https://doi.org/10.1136/pgmj.72.847.277 
8. Mater ZS. Clinical pattern of Acute pancreatitis. Internal J surgery. 2007; 11(1): 39-44. https://doi.org/10.5580/761

9. Munsell MA and Buscaglia JM. Acute pancreatitis. J Hosp Med. 2010; 5: 241-250. https://doi.org/10.1002/jhm.574

10. Stevens T, Parsi MA and Walsh RM. Acute Pancreatitis: problems in adherence to guidelines. Cleve Clin J Med. 2009; 76(12): 697-704. https://doi.org/10.3949/ccjm.76a.09060

11. Norton J, Berger G and Philip P. Acute \& Chronic Pancreatitis; Harrison's Principles of Internal Medicine. Newyork McGraw Hill. $20^{\text {th }}$ edition 2005; 1895-1906.

12. Miyake H, Harada H, Kunichika K, Ochi K and Kimura I. Clinical course and prognosis of chronic pancreatitis. Pancreas. 1987; 2(4):378-385

https://doi.org/10.1097/00006676-198707000-00003

13. Bhattacharya $\mathrm{S}$. The pancreas. Bailey and Love's short practice of surgery. $27^{\text {th }}$ ed. $2018 ; 1212-1239$.

14. Mofidi R, Patil PV, Suttie SA and Parks RW. Risk assessment in acute pancreatitis. Br J Surg. 2009; 96(2):137-150.

https://doi.org/10.1002/bjs.6431

15. Yeung Y, Yeung KLB and Wai CYA. APACHE system is better than Ranson system in prediction of severity of acute pancreatitis. Hapatobiliary Pancreat Dis Int. 2006; 5: 294-299.

16. Ahmed K, Ahad MA, Alim MA and Ekram A. Clinical profile of acute pancreatitis in a teaching hospital. Bangladesh Medical Journal Khulna. 2017; 49(1-2): 7-12. https://doi.org/10.3329/bmjk.v49i1-2.31818

17. Vengadakrishnan $\mathrm{K}$ and Koushik AK. A study of clinical profile of acute pancreatitis and its correlation with severity indices. International Journal of Health Sciences. 2015; 9 (4):410-417. https://doi.org/10.12816/0031230

18. Besselink MG, Verwer TJ, Schoenmaeckers EJ, Buskens E, Ridwan BU, Visser MR, et al. Timing of surgical intervention in necrotizing pancreatitis. Arch Surg. 2007; 142(12):1194-1201. https://doi.org/10.1001/archsurg.142.12.1194

19. Negi N, Mokta J, Sharma B, Sharma R, Jhobta A, et al. Clinical Profile and Outcome of Acute Pancreatitis: A Hospital- Based Prospective Observational Study in Subhimalayan State. J Assoc Physicians India. 2018; 66(3):22-24.

20. Baig SJ, Rahed A and Sen S. A prospective study of the etiology, severity and outcome opf acute pancreatitis in Eastern Indian. S Trop Gastroenterol 2008; 29:20-22.

21. Sivasankar $A$ and Kannan DG. Outcome of severe pancreatitis. Hepatobiliary pancreat Dis Int. 2006; 5(4): 599-604.

22. Ramu R, Paul V, Devipriya $S$ and Philip NC. Etiology, clinical profile and outcome of acute pancreatitis in a tertiary care teaching hospital in rural South India: a ten year retrospective study. Int Surg J. 2019; 6:3794-3799. https://doi.org/10.18203/2349-2902.isj20194443

23. Vengadakrishnan $\mathrm{K}$ and Koushik AK. A study of the clinical profile of acute pancreatitis and its correlation with severity indices. Int J Health Sci. 2015; 9(4):410-417. https://doi.org/10.12816/0031230

24. Raghuwanshi S, Gupta R, Vyas MM and Sharma R. CT Evaluation of Acute Pancreatitis and its Prognostic Correlation with CT Severity Index. J Clin Diagnos Res. 2016; 10(6):TC06TC11. https://doi.org/10.7860/JCDR/2016/19849.7934

25. Ahlawat $\vee$ and Godara R. Clinical Study of Demographic Profile, Etiology, Severity and Outcome of Acute Pancreatitis in a Tertiary Care Teaching Hospital in Northern India. J Gastrointest Dig Syst. 2018; 8:575.

https://doi.org/10.4172/2161-069X.1000575

\section{Author Contributions:}

SKD- Concept and design of the study, review of literature, data collection, interpretation of result, critical review of manuscript; SD- Concept of study, review of literature, manuscript preparation, data analysis and interpretation, critical review of manuscript.

\section{Work attributed to:}

Tripura Medical College and Dr. B R Ambedkar Hospital, Agartala, Tripura

\section{ORCID ID:}

Dr. Surajit Kumar Das- (10 https://orcid.org/0000-0003-0445-2509

Dr. Saswati Das- (i) https://orcid.org/0000-0002-4548-0066 